\title{
SELEÇÃO INDIRETA PARA TEOR DE 2-TRIDECANONA EM TOMATEIROS SEGREGANTES E SUA RELAÇÃO COM A RESISTÊNCIA À TRAÇA-DO-TOMATEIRO1
}

\author{
CLÁUDIA REGINA GONTIJO LABORY², LENIRA VIANA COSTA SANTA-CECÍLIA ${ }^{3}$, WILSON ROBERTO MALUF4, \\ MARIA DAS GRAÇAS CARDOSO5 ${ }^{5}$ EDUARDO BEARZOTTI' ${ }^{6}$ e JOÃO CÂNDIDO DE SOUZA7
}

\begin{abstract}
RESUMO - Este trabalho teve como objetivo verificar a relação entre o teor de 2-tridecanona (2-TD) em materiais selecionados e o nível de resistência à traça-do-tomateiro (Tuta absoluta (Meyrick, 1917) (Lepidoptera: Gelechiidae)) em gerações avançadas de Lycopersicon spp. derivado de cruzamentos interespecíficos. Foi usada uma população de tomateiros segregantes (geração $\mathrm{F}_{4} \mathrm{RC} \mathrm{C}_{2}$ ) para 2-TD, uma metilcetona que confere resistência à traça-do-tomateiro. Genótipos foram selecionados e avaliados quanto à resistência do tipo não-preferência: três materiais com alto teor do aleloquímico 2-TD (HI1, HI2, HI3) e dois materiais com baixo teor (LO1, LO2), além das testemunhas. Após infestação controlada, foram avaliados: contagem do número de ovos postos, evolução da lesão nos folíolos, porcentagem de folíolos atacados, e índice geral de lesão causada pela traça. Plantas com alto teor de 2-TD (HI1 e HI3) tiveram uma baixa progressão das lesões ocasionadas pelo ataque de T. absoluta. A planta LO1 foi muito atacada pela praga, o mesmo não ocorrendo com a planta LO2, que foi infestada acidentalmente por ácaros do gênero Tetranychus, acarretando, provavelmente, uma disputa de nicho ecológico entre os dois artrópodes. Concluiu-se que altos teores de 2-TD estão ligados a mecanismos de resistência à traça-do-tomateiro do tipo não-preferência por oviposição e alimentação.
\end{abstract}

Termos para indexação: Lycopersicon hirsutum, Lycopersicon esculentum, Tuta absoluta, resistência de plantas, antixenose, metilcetona.

\section{INDIRECT SELECTION TO 2-TRIDECANONE CONTENT AND ITS RELATION TO TOMATO PINWORM RESISTANCE}

\begin{abstract}
This work had the objective to verify the relation between 2-tridecanone (2-TD) in selected plants and resistance level to tomato pinworm (Tuta absoluta (Meyrick, 1917) (Lepidoptera: Gelechiidae)) in advanced generations of Lycopersicon spp. interspecific crosses. It was used a tomato population $\left(\mathrm{F}_{4} \mathrm{RC}_{2}\right.$ generation) segregant for 2-TD, a methyl ketone that controls the resistance of the tomato pinworm. Materials were selected and evaluated for a non-preference mechanism of resistance. Three genotypes with high level of the allelochemic 2-TD (HI1, HI2, HI3), two with low level (LO1, LO2) and two check genotypes were used. After a controlled infestation, oviposition preference, type and percent of leaflet damage, and damage index caused by the tomato pinworm were evaluated. Plants with high level of 2-TD (HI1, HI3) had a low progression of leaflet damage by Tuta absoluta. The LO1 genotype was much attacked by the tomato pinworm, while the LO2 genotype was accidentally attacked by acari of the Tetranychus genus, probably causing a dispute between the two arthropods. It was concluded that 2-TD high levels are associated to non-preference ovipositions and feeding resistance mechanisms to tomato pinworm.
\end{abstract}

Index terms: Lycopersicon hirsutum, Lycopersicon esculentum, Tuta absoluta, plant resistance, antixenose, methyl ketone.

\footnotetext{
${ }^{1}$ Aceito para publicação em 2 de outubro de 1998.

${ }^{2}$ Enga Agra, M.Sc., Dep. de Biologia, Universidade Federal de

Lavras (UFLA), Caixa Postal 37, CEP 37200-000 Lavras, MG

${ }^{3}$ Enga Agra $\underline{a}$, M.Sc., EPAMIG, Caixa Postal 176, CEP 37200-000 Lavras, MG. E-mail: scecilia@ufla.br
}

\footnotetext{
${ }^{4}$ Eng. Agr., Ph.D., Dep. de Fitotecnia, UFLA.

${ }^{5}$ Eng. Agr., Ph.D., Dep. de Química, UFLA.

${ }^{6}$ Eng. Agr., Ph.D., Dep. de Ciências Exatas, UfLA.

${ }^{7}$ Eng. Agr., M.Sc., Dep. de Genética, UfLA. E-mail: cansouza@ufla.br
} 


\section{INTRODUÇÃO}

Uma das mais importantes hortaliças cultivadas, o tomate, Lycopersicon esculentum (Mill), produto de sucessivas seleções para que se chegasse a sua forma atual, teve sua variabilidade genética restringida, o que provavelmente ocasionou perda de importantes genes de resistência a pragas, dentre elas, à traça-do-tomateiro Tuta absoluta (Meyrick, 1917) (Lepidoptera: Gelechiidae). Sendo hoje a principal praga da cultura, é responsável pela diminuição drástica da área cultivada de tomateiros nos últimos anos (Haji, 1992). A necessidade de novas alternativas para o controle de pragas tem conduzido profissionais da área a estudos visando ao desenvolvimento de cultivares resistentes.

Stoner (1970) relata que trabalhos têm sido desenvolvidos para transferência de resistência às espécies cultivadas, e que cultivares resistentes a determinados insetos foram utilizadas por vários anos nos Estados Unidos e Europa, com intuito de reduzir o impacto do uso de inseticidas no meio ambiente.

No Brasil, estão em desenvolvimento programas de melhoramento buscando resistência varietal a insetos, a partir de germoplasmas silvestres que apresentem fatores de resistência (Barona et al., 1989); os resultados deste programa são bastante modestos, e os atuais níveis de resistência das cultivares comerciais não são suficientemente altos para possibilitar redução na quantidade de agroquímicos utilizados.

Juvik et al. (1982) sugerem que fatores presentes em introduções silvestres poderão ser incorporados de modo mais simplificado e mais eficiente nas cultivares comerciais, se a seleção das plantas puder ser feita com base em algumas características de fácil constatação. Há relatos de boas fontes de resistência a artrópodes nas espécies Lycopersicon hirsutum f. glabratum C.H. Müll (PI 134417), L. hirsutum f. hirsutum (PI 126445), L. pennelli e L. peruvianum, porém sem valor comercial.

Dentre os materiais selvagens de tomateiro, destaca-se L. hirsutum f. glabratum C.H. Müll (PI 134417), que apresenta os aleloquímicos 2-tridecanona (2-TD) e 2-undecanona (2-UD), substâncias que têm sido citadas como responsáveis pela resistência a várias pragas (Willians et al., 1980; Dimock \& Kennedy, 1983; Kennedy, 1984; Lin et al., 1987; Farrar Junior \& Kennedy, 1988).

Willians et al. (1980) foram os primeiros a relatar a ocorrência de 2-tridecanona (2-TD), uma substância tóxica a insetos, em folíolos do tomateiro L. hirsutum f. glabratum. A 2-TD é uma metilcetona encontrada no L. hirsutum f. glabratum numa quantidade 72 vezes superior à encontrada no L. esculentum. Dimock \& Kennedy (1983) constataram a ocorrência dessa metilcetona exclusivamente na superfície dos folíolos do PI 134417, estabelecendo uma correlação positiva significativa entre a concentração de 2-TD e a densidade do tricoma glandular tipo VI, as quais são fortemente relacionadas à resistência dos artrópodes.

Barbosa (1994) demonstrou que a resistência à T. absoluta em cruzamento interespecífico de L. esculentum $\mathrm{x}$ L. hirsutum f. glabratum (PI 134417) está relacionada ao teor de 2-TD nos folíolos. Plantas $F_{2}$ com alto teor de 2-TD apresentam nível de resistência semelhante ao do L. hirsutum f. glabratum, enquanto plantas com baixo teor de 2-TD têm grau de susceptibilidade semelhante ao do L. esculentum. A herdabilidade no sentido amplo do teor de 2-TD foi estimada em $60,58 \%$, mas não foi obtida uma estimativa da herdabilidade no sentido restrito, em virtude de desvios da segregação mendeliana existentes no cruzamento interespecífico. Esses desvios tendem a ser de menor importância à medida que venha a predominar o genoma do L. esculentum, ou seja, em retrocruzamentos subseqüentes na espécie cultivada, quando, então, estimativas menos tendenciosas de herdabilidade poderão ser obtidas.

A presença de tricomas é um dos fatores morfológicos que mais influem no comportamento dos insetos, sendo, em alguns casos, um fator de susceptibilidade, e noutros, de resistência. Quando se trata de tricomas normais, em densidade e tamanho, eles podem atuar diretamente sobre o indivíduo, afetando a sua oviposição, sua alimentação, sua locomoção ou seu comportamento em relação ao abrigo fornecido (Lara, 1991).

Segundo Giustolin (1991) e Giustolin \& Vedramin (1994), essas cetonas constituem-se como mecanismo de resistência por meio de antixenose e 
antibiose. Relatos na literatura a respeito dos tipos de tricomas glandulares são verificados em híbridos $\mathrm{F}_{1}$ (Snyder \& Carter, 1985), $\mathrm{F}_{2}$ (Carter \& Snyder, 1986) e retrocruzamentos (Sorenson et al., 1989) de L. esculentum X L. hirsutum, sendo-lhes atribuídos efeitos de antixenose em artrópodes(Carter \& Snyder, 1985; Kennedy \& Sorenson, 1985), em decorrência de exsudatos de fenóis, sesquiterpenóides e metilcetonas (Sorenson et al., 1989).

Atualmente, com a disponibilidade de técnicas colorimétricas de baixo custo para a quantificação destes aleloquímicos nas folhas de tomateiro (Barbosa, 1994), novas perspectivas são abertas para o melhoramento, visando resistência e uma seleção precisa a artrópodes, com baixo custo e ação não-destrutiva em relação à planta.

Em virtude dos prejuízos econômicos que a traça-do-tomateiro pode causar em todas as regiões produtoras de tomate no Brasil, desenvolveu-se o presente trabalho objetivando-se avaliar resistência do tipo não-preferência por essa praga em gerações avançadas $\left(\mathrm{F}_{4} \mathrm{RC}_{2}\right)$ de materiais de tomateiros melhorados.

\section{MATERIAL E MÉTODOS}

O presente trabalho foi conduzido em condições de casa de vegetação sob temperatura de $24^{\circ} \mathrm{C} \pm 2{ }^{\circ} \mathrm{C}$ e umidade relativa de $78 \% \pm 10 \%$, na Universidade Federal de Lavras, com início em janeiro de 1994. Avaliou-se a distribuição de 2-TD em gerações $\mathrm{F}_{4} \mathrm{RC}_{2}$ (mais avançadas) de tomateiros provenientes de novos retrocruzamentos, tendo L. esculentum (TSWV 556, baixo teor de 2-TD) como pai recorrente e L. hirsutum f. glabratum (PI 134417, alto teor de 2-TD) como fonte de resistência.

Após avaliação química, relativa à quantificação da 2-TD nos materiais selecionados da geração $\mathrm{F}_{4} \mathrm{RC}_{2}$, foram escolhidas cinco plantas para uma nova avaliação de resistência à traça-do-tomateiro. Das cinco plantas, três apresentaram a característica de alto teor de 2-TD (HI1, $\mathrm{HI} 2$ e HI3, mais de $200 \times 10^{-12}$ moles $\mathrm{cm}^{-2}$ de 2-TD), e as duas outras, de baixo teor (LO1 e LO2, $70 \times 10^{-12}$ a $110 \times 10^{-12}$ moles $\mathrm{cm}^{-2}$ de 2-TD). Como testemunhas, foram utilizados os respectivos progenitores com referência a alto (PI 134417) e baixo teor (TSWV 556) de 2-TD. Para evitar uma possível infestação natural da praga, todos os materiais foram mantidos isolados até alcançarem o tamanho ideal para infestação.
Insetos ainda na fase jovem foram coletados em campo e posteriormente submetidos à criação em condições de laboratório. Adultos machos e fêmeas foram sexados na fase de crisálidas (pupa) e mantidos separados até a infestação das plantas. A sexagem foi feita com base no dimorfismo sexual observado na porção terminal do abdome das crisálidas. No macho, essa porção é arredondada distalmente, com margem lisa, enquanto nas fêmeas essa porção apresenta-se com uma margem larga e levemente arredondada (Coelho \& França, 1987).

Para obtenção dos clones, brotações axilares de tamanhos homogêneos das plantas-matrizes foram destacadas, mergulhadas em água (para não ressecar), e então fixadas em substrato comercial acrescido de casca de arroz carbonizada colocado em bandejas de isopor de formato piramidal (128 células). As estacas, em bandejas, foram mantidas sob a proteção de sombrite preto $(50 \%)$, até o enraizamento completo. Quando aptas, foram transplantadas para vasos, nos quais foram mantidas até o tamanho de $60 \mathrm{~cm}$ aproximadamente (50 dias após a clonagem). Depois, foram transferidas para as gaiolas, onde foi realizada a infestação artificial com os adultos virgens da traça-do-tomateiro. Os materiais foram infestados na proporção de 1 macho para 1,32 fêmea (Haji et al., 1988) perfazendo um total de 13 machos para 21 fêmeas por bloco.

O delineamento experimental foi em blocos casualizados, com sete tratamentos e três repetições (sendo cada parcela constituída de um vaso com um clone), mantidas em gaiolas especiais, para infestação, que constituíam os blocos. Aos dez dias da infestação artificial, período necessário ao acasalamento e postura dos insetos, realizou-se o teste de livre escolha para avaliar a resistência do tipo não-preferência por oviposição através da contagem dos ovos distribuídos na posição inferior, mediana e superior das plantas de cada tratamento. As avaliações foram executadas por cinco pessoas distintas. A média dos cinco avaliadores constituiu a nota média para cada parcela e tipo de avaliação. Foi formulada uma escala própria de notas, que variava de 0 a 5 em níveis progressivos de lesão e coalescência nos folíolos.

Aos 17, 24 e 31 dias após a infestação, foi avaliado o tipo de lesão nos folíolos, utilizando-se a seguinte escala de notas: 0 - nenhuma lesão nos folíolos; 1 - lesões pequenas e pouco numerosas; 2 - lesões pequenas e médias, pouco numerosas, localizadas freqüentemente nos bordos dos folíolos; 3 - lesões médias e grandes, numerosas e coalescentes, bordos dos folíolos deformados; 4 - lesões grandes, coalescentes, folíolos completamente deformados; 5 - lesões tomando todo o folíolo. Por meio de um sistema de notas, independentemente do número ou ta- 
manho da lesão, 31 dias após a infestação avaliou-se a porcentagem de folíolos atacados seguindo este critério: 0 - $0 \%$ de folíolos atacados; 1 - 0,1 a $5 \%$ de folíolos atacados; 2 - 5,1 a $20 \%$ de folíolos atacados; $3-20,1$ a $50 \%$ de folíolos atacados; $4-50,1$ a $80 \%$ de folíolos atacados; $5-80,1$ a $100 \%$ de folíolos atacados.

Para uma melhor visualização do dano causado pela traça, foram multiplicadas as notas da última avaliação, atribuídas às lesões nos folíolos, e as notas de percentagem de folíolos atacados, obtendo-se o índice geral da lesão, que pode variar de 0 a 25 .

\section{RESULTADOS E DISCUSSÃO}

Teste sobre não-preferência em relação à oviposição da traça-do-tomateiro mostrou diferenças significativas entre genótipos, sendo particularmente evidentes na posição superior da planta (Tabela 1). Os genótipos HI1 e HI3 se destacaram como os menos preferidos para oviposição, e inferiores apenas em relação à testemunha resistente selvagem PI 134417 (L. hirsutum f. glabratum). Nas posições mediana e inferior das plantas, as diferenças entre genótipos foram menos marcantes, e supõe-se que sejam as regiões das plantas mais velhas e menos tenras não-preferidas por não garantirem a perpetuação da espécie.

No teste sobre não-preferência em relação à alimentação, observou-se que nas avaliações referentes a lesões nos folíolos, realizadas aos 17, 24 e 31 dias que se seguiram à infestação artificial da traçado-tomateiro nos genótipos estudados, houve uma evolução diferenciada das lesões em cada genótipo. O comportamento dos genótipos LO1, LO2, HI2,
HI3 e TSWV 556 foram satisfatoriamente explicados pela equação de regressão linear. Para o genótipo HI1, como os modelos polinomiais não apresentaram bons ajustes, utilizou-se o modelo de regressão dado por $\mathrm{Y}=\mathrm{a}+\mathrm{b} / \mathrm{x}$. No caso do genótipo PI 134417, nenhuma das regressões foi significativa, por não terem as lesões progredido no decorrer de cada época (Tabela 2).

As curvas das regressões de cada genótipo são demonstradas na Fig. 1. A testemunha TSWV 556 apresentou as maiores lesões, em comparação às dos demais tratamentos.

Entre os genótipos testados, com exceção da testemunha selvagem PI 134417 e LO2 - cuja menor oviposição da traça-do-tomateiro pode ser atribuída à infestação por ácaros (Tetranychus sp.) - os genótipos HI1 e HI3 apresentaram as menores lesões. LO1 e HI2 exibiram as maiores velocidades de evolução de lesões, superadas apenas pela testemunha TSWV 556. Esses resultados confirmam relatos a respeito da ocorrência da 2-tridecanona (2-TD) em folíolos de tomateiro L. hirsutum f. glabratum Willians et al. (1980), Barbosa (1994) e Giustolin \& Vedramin (1994).

Aos 31 dias após a infestação, foi avaliada também a porcentagem de folíolos atacados pela traçado-tomateiro. Nesta avaliação, não se considerou número e tamanho de lesões no folíolo, e sim, qualquer tipo de lesão causada pela traça-do-tomateiro.

Usando o teste de agrupamento univariado de Scott \& Knott (1974), os genótipos se comportaram da seguinte forma: no primeiro grupo, ficou apenas o genótipo PI 134417, com uma média bem baixa

TABELA 1. Médias de oviposição na posição inferior, mediana e superior dos genótipos utilizados segundo agrupamento univariado de Scott \& Knott (1974), a 5\% de probabilidade. UFLA, Lavras, MG, 1996.

\begin{tabular}{lccr}
\hline \multirow{2}{*}{ Tratamentos } & \multicolumn{3}{c}{ Posição na planta } \\
\cline { 2 - 4 } & Inferior/grupos & Mediano/grupos & Superior/grupos \\
\hline LO1 & $14,09(2)$ & $25,16(2)$ & $28,53(3)$ \\
LO2 & $2,18(1)$ & $3,60(1)$ & $6,05(1)$ \\
HI1 & $1,87(1)$ & $21,55(2)$ & $15,52(2)$ \\
HI2 & $7,98(2)$ & $31,56(2)$ & $53,26(4)$ \\
HI3 & $4,68(1)$ & $18,66(2)$ & $8,64(2)$ \\
TSWV 556 & $10,19(2)$ & $6,31(1)$ & $65,32(4)$ \\
PI 134417 & $0,97(1)$ & $1,61(1)$ & $1,92(1)$ \\
\hline
\end{tabular}


de folíolos atacados; no segundo grupo, ficou o genótipo LO2 - que apresentava alta infestação por ácaros e que pode ter interferido no comportamento da traça. Os demais genótipos (LO1, HI1, HI2, HI3 e TSWV 556) estão dispostos num terceiro grupo, no qual houve, em média, um grande número de folíolos infestados, independentemente do nível de ataque determinado pelo tipo de lesão (Tabela 3).

Esses resultados estão de acordo com os encontrados por Barbosa (1994), onde plantas com alto teor de 2-TD apresentam pequena magnitude de dano nos folíolos, pequena porcentagem de folíolos atacados, e lenta evolução dos danos na planta.
Sendo os tratamentos divididos em três grupos, os genótipos PI 134417, HI3, e HI2 são pertencentes ao primeiro grupo, que, pelas médias das notas, demonstram não terem sido muito atacados pelo ácaro; ao segundo grupo, os genótipos LO1 e HI1, que estavam ligeiramente infestados por ácaros; e ao terceiro grupo, o genótipo LO2 e a testemunha TSWV 556, ambos com baixo teor de 2-TD. O genótipo LO2 atípico com relação ao porte, apresenta-se estiolado e com poucas folhas, e o dano nele causado pelo ataque do ácaro acabou por impedir a infestação da traça-do-tomateiro. Já a testemunha TSWV 556, também altamente infestada por ácaros,

TABELA 2. Análise de variância relativa ao desdobramento da interação entre os fatores genótipo e época, em relação à evolução de lesão dos folíolos atacados, avaliados aos 17, 24 e 31 dias após a infestação artificial com Tuta absoluta. Temperatura de $25 \pm 2^{\circ} \mathrm{C}$ e umidade relativa de $75 \% \pm 10 \%$. UFLA, Lavras, MG, 1996.

\begin{tabular}{lcc}
\hline Fatores da variação & Grau de liberdade & Quadrado médio \\
\hline Época dentro de LO1 & $(2)$ & $4,567^{*}$ \\
Regressão linear & 1 & 0,036 \\
Regressão quadrática & 1 & \\
Época dentro de LO2 & $(2)$ & $2,407^{*}$ \\
Regressão linear & 1 & 0,002 \\
Regressão quadrática & 1 & \\
Época dentro de HI1 & $(2)$ & $1,739^{*}$ \\
Regressão Hiperbólica & 1 & 0,030 \\
Desvio & 1 & \\
Época dentro de HI2 & $(2)$ & $3,840^{*}$ \\
Regressão linear & 1 & 0,222 \\
Regressão quadrática & 1 & \\
Época dentro de HI3 & $(2)$ & $2,407^{*}$ \\
Regressão linear & 1 & 0,269 \\
Regressão quadrática & 1 & \\
Época dentro de TSWV 556 & $(2)$ & $9,627^{*}$ \\
Regressão linear & 1 & 0,320 \\
Regressão quadrática & 1 & 0,027 \\
Época dentro de PI 134417 & $(2)$ & 0,009 \\
Regressão linear & 1 & \\
Regressão quadrática & 1 & \\
Resíduo combinado & 16,66 & \\
\hline
\end{tabular}

* Significativo a $5 \%$ de probabilidade. 
possui avantajada área foliar, o que provavelmente fez com que a presença do ácaro não impedisse também a infestação da traça-do-tomateiro (Tabela 4).

A partir das notas atribuídas ao tipo de lesão e à porcentagem de folíolos atacados, foi calculado o índice geral de lesão para cada tratamento. Uma vez associadas as duas características, obteve-se uma relação do dano geral causado pela traça em cada genótipo (Tabela 5).

Os genótipos diferiram de forma marcante quanto ao índice geral de lesão, que variou de 0 a 25 . Em

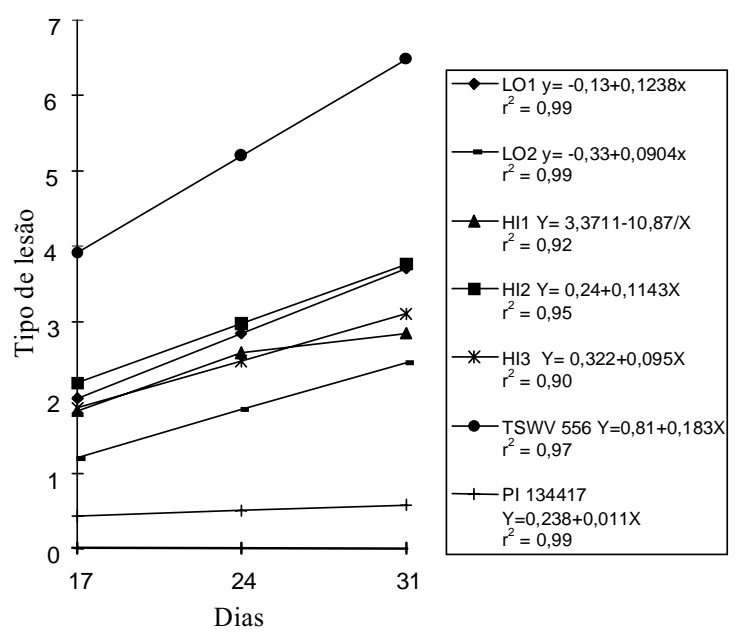

FIG. 1. Evolução do tipo de lesão causada por Tuta absoluta em folíolos de tomateiro em função dos genótipos de tomateiro com teores variáveis de 2-Tridecanona.

TABELA 3. Agrupamento univariado de Scott \& Knott (1974), a 5\% de probabilidade, para as notas referentes à porcentagem de folíolos atacados por Tuta absoluta, em diferentes genótipos de tomateiro. UFLA, Lavras, MG, 1996.

\begin{tabular}{lc}
\hline Tratamentos & Médias/grupos \\
\hline LO1 & $4,00(3)$ \\
LO2 & $1,93(2)$ \\
HI1 & $3,86(3)$ \\
HI2 & $4,60(3)$ \\
HI3 & $3,26(3)$ \\
TSWV 556 & $4,46(3)$ \\
PI 134417 & $1,00(1)$ \\
\hline
\end{tabular}

função deste índice, os genótipos foram classificados em grupos. O genótipo PI 134417 se encontra no grupo um, com um índice geral de 0,47 de lesão. O genótipo LO2 fica no segundo grupo, também com baixo índice de 5,73, explicado anteriormente por um severo ataque de ácaros. No terceiro grupo, considerado promissor quanto à resistência, encontramse os genótipos HI1 e HI3, com um índice razoável de lesão, respectivamente, 10,13 e 11,33. Os genótipos LO1 e HI2 se encontram no quarto grupo, apresentando um índice de 14,83 e 16,27. A testemunha TSWV 556, com baixo teor de 2-TD, se encontra no quinto grupo, onde obteve um índice de 21,467 .

Os genótipos HI1 e HI3 evidenciaram maior resistência à traça-do-tomateiro. Assim, os vários ci-

TABELA 4. Agrupamento univariado de Scott \& Knott, (1974), a 5\% de probabilidade, para infestação acidental do ácaro Tetranychus urticae, em diferentes genótipos de tomateiro. UFLA, Lavras, MG, 1996.

\begin{tabular}{lc}
\hline Tratamentos & Médias/grupos \\
\hline LO1 & $0,93(2)$ \\
LO2 & $3,15(3)$ \\
HI & $1,52(2)$ \\
HI2 & $0,49(1)$ \\
HI3 & $0,43(1)$ \\
TSWV 556 & $3,50(3)$ \\
PI 134417 & $0,00(1)$ \\
\hline
\end{tabular}

TABELA 5. Agrupamento univariado de Scott \& Knott (1974), a 5\% de probabilidade, para índice geral de lesão do folíolos atacados por Tuta absoluta, em diferentes genótipos de tomateiro. UFLA, Lavras, MG, 1996.

\begin{tabular}{lc}
\hline Tratamentos & Médias/grupos \\
\hline LO1 & $14,83(4)$ \\
LO2 & $5,73(2)$ \\
HI1 & $11,33(3)$ \\
HI2 & $16,27(4)$ \\
HI3 & $10,13(3)$ \\
TSWV 556 & $21,47(5)$ \\
PI 134417 & $0,47(1)$ \\
\hline
\end{tabular}


clos de seleção indireta, efetuados para alto teor de 2-TD após retrocruzamentos e autofecundações, e a existência, em $\mathrm{F}_{4} \mathrm{RC}_{2}$, de, pelo menos, dois genótipos (HI1 e HI3), que aliam alto teor de 2-TD a bom nível de resistência à traça, são indicações de que a 2-TD, uma metilcetona, deve ser o principal fator envolvido na resistência à $T$. absoluta em populações derivadas do cruzamento interespecífico de L. esculentum x L. hirsutum f. glabratum.

Por ocasião da primeira avaliação, foi observada uma grande incidência do ácaro Tetranychus urticae Koch (1836) (Acari: Tetranychidae). Uma das plantas registradas com baixo teor de 2-TD (LO2) foi muito pouco ou quase nada atacada pela traça-dotomateiro provavelmente por já ter havido uma préinfestação por outro artrópode.

O método de seleção via análise de 2-tridecanona em plantas de tomate pode servir, se não para seleção inequívoca, pelo menos para descarte de materiais, antes de levá-los para testes em casa de vegetação e campo.

\section{CONCLUSÕES}

1. A seleção de plantas em geração mais avançada do Lycopersicon spp. derivada de cruzamentos interespecíficos, com alto teor de 2-tridecanona, constituem efetivo critério de seleção indireta de plantas resistentes à $T$. absoluta.

2. Altos teores de 2-tridecanona em plantas da geração $\mathrm{F}_{4} \mathrm{RC}_{2}$ de Lycopersicon spp., estão vinculados aos mecanismos de resistência à T. absoluta do tipo não-preferência por oviposição e não-preferência por alimentação.

\section{REFERÊNCIAS}

BARBOSA, L.V. Controle genético e mecanismos de resistência em Lycopersicon spp. à traça-do-tomateiro [Scrobipalpuloides absoluta (Meyrick, 1917) (Lepidoptera: Gelechiidae)]. Lavras: ESAL, 1994. 69p. Tese de Mestrado.

BARONA, G.H.; PARRA, S.A.; VALLEJO, C.F.A. Evaluación de especies silvestres de Lycopersicon sp., como fuente de resistencia a Scrobipalpula absoluta (Meyrick) y su intento de transferencia a Lycopersicon esculentum Mill. Acta Agronômica, Palmira, v.39, n.1/2, p.34-45, ene./jun. 1989.
CARTER, C.D.; SNYDER, J.C. Mite responses and trichome characters in a full sib $F_{2}$ family of Lycopersicon esculentum $x$ L. hirsutum. Journal of the American Society for Horticultural Science, Alexandria, v.111, n.1, p.130-133, Jan. 1986.

CARTER, C.D.; SNYDER, J.C. Mite responses in relation to Trichomes of Lycopersicon esculentum $\mathrm{X}$ L. hirsutum $\mathrm{F}_{2}$ hibrids. Euphytica, Wageningen, v.34, n.1, p.177-185, Mar. 1985.

COELHO, M.C.F.; FRANÇA, F.H. Biologia e quetotaxia da larva e descrição da pupa e adulto da traça-dotomateiro. Pesquisa Agropecuária Brasileira, Brasília, v.22, n.2, p.129-135, fev. 1987.

DIMOCK, M.B.; KENNEDY, G.G. The role of glandular trichomes in the resistence of Lycopersicon hirsutum f. glabratum to Heliohis zea. Entomologia Experimentalis et Applicata, Dordrecht, v.33, p.263-268, 1983.

FARRAR JUNIOR, R.R.; KENNEDY, G.G. 2-Undecanona, a pupal mortality in Heliothis zea sensitive larval stage and "in planta" activity in Lycopersicon hirsutum f. glabratum. Entomologia Experimentalis et Applicata, Dordrecht, v.47, n.3, p.205-210, June 1988.

GIUSTOLIN, T.A. Efeito dos aleloquímicos 2-tridecanona e 2-undecanona presentes em Lycopersicon spp. sobre a biologia da traça-dotomateiro, Scrobipalpuloides absoluta (Meyrick, 1917) (Lep.: Gelechiidae). Piracicaba: ESALQ, 1991. 155p. Tese de Mestrado.

GIUSTOLIN, T.A.; VEDRAMIN, J.D. Efeito de duas espécies de tomateiro na biologia de Scrobipalpuloides absoluta (Meyrick). Anais da Sociedade de Entomologia do Brasil, v.23, n.3, p.511-517, 1994.

HAJI, F.N.P. Histórico e situação atual da traça do tomateiro nos perímetros irrigados do submédio do São Fransisco. In: SIMPÓSIO DE CONTROLE BIOLÓGICO, 3., 1992, Águas de Lindóia. Anais... Jaguariúna: Embrapa-CNPDA, 1992. p.57-59.

HAJI, F.N.P.; PARRA, J.R.P.; SILVA, J.P.; BATISTA, J.G.S. Biologia da traça do tomateiro sob condições de laboratório. Pesquisa Agropecuária Brasileira, Brasília, v.23, n.2, p.107-110, fev. 1988.

JUVIK, J.A.; STEVENS, M.A.; RICK, C.M. Survey of the genus Lycopersicon for variability in tomatine content. Horticultural Science, Alexandria, v.5, n.17, p.764-766, Oct. 1982.

Pesq. agropec. bras., Brasília, v.34, n.5, p.733-740, maio 1999 
KENNEDY, G.G. 2-Tridecanone, tomatoes and Heliothis $z e a$. Potential incompatibility of plant antibiosis with insecticial control. Entomologia Experimentalis et Applicata, Dordrecht, v.35, n.3, p.305-311, Feb. 1984.

KENNEDY, G.G.; SORENSON, C.F. Role of glandular trichomes in the resistance of Lycopersicon hirsutum f. glabratum to Colorado Potato Beetle (Coleoptera: Chrysomelidae). Journal of Economic Entomology, Madison, v.78, n.3, p.547-551, 1985.

LARA, F.M. Princípios de resistência de plantas aos insetos. 2.ed. São Paulo: Ícone, 1991. 336p.

LIN, S.Y.H.; TRUMBLE, J.T.; KUMAMOTO, J. Activity of volatile compounds in glandular trichomes of Lycopersicon species against two insect herbivores. Journal of Chemical Ecology, New York, v.13, n. 4, p.837-850, 1987

SCOTT, A.J.; KNOTT, M.A. Cluster analyses method for grouping means in the analysis of variance. Biometrics, Raleigh, v.30, p.507-512, 1974.
SNYDER, J.C.; CARTER, C.D. Trichomes on leaves of Lycopersicon hirsutum, Lycopersicon esculentum and their hybrids. Euphytica, Wageningen, v.34, p.53-64, 1985 .

SORENSON, C.E.; FERY, R.L.; KENNEDY, G.G Relationship between Colorado Potato Beetle (Coleoptera - Chrysomelidae) and Tobbaco Hornwrm (Lepidoptera - Sphingidae) resistance in Lycopersicon hirsutum f. glabratum. Journal of Economic Entomology, Madison, v.82, n.6, p.1743-1748, 1989.

STONER, A. Breeding for insect resistance in vegetables. HortScience, Alexandria, v.5, n.2, p.76-79, Apr. 1970.

WILLIAMS, W.G.; KENNEDY, G.G.; YAMAMOTO, R.T.; THACKER, J.D; BORDNER, J. 2-tridecanona - a naturally occurring insecticide from the wild tomato Lycopersicon hirsutum f. glabratum. Science, Washington, DC, v.27, p.888-889, 1980 . 